\title{
Innovations
}

\section{The rise and fall of a community service for the 'compulsory' treatment of opiate addicted offenders}

\author{
ERIC F. Mendelson, Consultant Forensic Psychiatrist, Knowle Hospital, Fareham, \\ Hampshire PO17 5NA and STEPHEN P. MASON, Probation Officer, Community Service \\ Unit, 12 Minshull Street, Manchester M1 3FR
}

The compulsory treatment of addicts has always attracted controversy and even generates strong emotional responses from workers in the field. But the few projects which have been mounted have yielded results no less encouraging than voluntary approaches and in some instances report greater success. These schemes have already been subject to an international comparison (Webster, 1986).

We hope this description of our experience will be useful to those intending to advance this approach in Britain. The full characteristics of the patients and their outcome will be reported in another paper. This article will address service and interdisciplinary issues.

\section{The service}

The treatment approach was multidisciplinary and comprehensive; full details can be obtained on request.

Cases were accepted only if the courts had imposed a probation order with a condition of treatment: this was under Section 3 of the Powers of the Criminal Courts Act 1973, using the requirement, "treatment by or under the direction of such duly qualified medical practitioner as may be specified in the order". To emphasise the potential pitfalls and expectations a written description of the service was given to all the prospective patients.

Our clinic was held over 18 months during 1985 and 1986 in a central probation office in Manchester.

\section{The initial resistance from the probation service}

Although some in the probation service appeared keen to support the project, many objected to the tenet of mandatory treatment. For example, one officer wrote "... my main worry concerns the issue of whether it is right or indeed possible to enforce something defined by somebody as good for some- body else". It is often argued that clients facing prison sentences have no choice in accepting alternative disposals and therefore do not properly consent. However, we felt that there was still a choice, although perhaps difficult to accept. More important, motivation is difficult to judge. Psychiatric practice regularly encounters reluctant cases who with time become more convinced and committed to the benefits of treatment.

But as many probation officers seemed to harbour objections, and were not referring cases, a survey was performed to investigate attitudes.

\section{A survey of the attitudes of the probation officers}

All the probation officers in central Manchester were surveyed; 44 completed questionnaires were returned. Unfortunately several of the probation teams answered collectively by discussing the issues and reached a consensus over the questions. No doubt this had a slight moderating effect on the overall results. We estimated at least half the officers responded. The forms consisted of statements to which the officers could reply by marking a category along the continuum: strongly agree, agree, not sure, disagree, strongly disagree. There were ample prompts to elicit further comments, but those obtained centred on the problems already noted.

Interestingly, none admitted to forgetting about the existence of the service. Only $4 \%$ were against the service in principle. But $18 \%$ were opposed to the compulsory nature of the treatment and a further $34 \%$ were not sure. Slightly less, $12 \%$, thought our treatment programme was inappropriate for this group of offenders and $24 \%$ were unsure. Curiously, as many as $40 \%$ stated there were very few suitable candidates and another $28 \%$ were unsure. This was most surprising, both in view of our observations and those of others in the field. Few, $7 \%$, with just $12 \%$ unsure, thought that suitable candidates would be 
imprisoned anyway, regardless of their recommendations. The majority, $84 \%$, did not think that the extra work involved in implementing and managing a probation order with a condition of treatment discouraged referral to the project. Indeed only one response indicated that it would. Again, surprisingly to us, $65 \%$ were not sure whether individuals would be willing to attend and $14 \%$ felt that they would be unwilling. Our impressions were that very few offenders would prefer to be in prison and suffer the usual abrupt withdrawal and enforced abstinence. Although illicit drugs are undoubtedly available in prison, the supply is unlikely to meet the addict's requirements.

If the officers thought that their clients would be unwilling to attend our clinic, they were invited to answer further questions. This produced a greater response than the direct question, and responses were obtained in 20 returns ( $45 \%$ ). Thirty per cent of these indicated that clients would have transport problems, while $16 \%$ confirmed the suggestion 'too many problems at home'. Perhaps more significantly, $28 \%$ thought that clients would be unwilling to tackle their problems while still resident in the community, as they would prefer the asylum of a hospital or a drug rehabilitation hostel. But most frequently affirmed, in $74 \%$, was the statement that clients tend to deny that they have a drug problem!

In conclusion, we found the probation officers less positive about our service than we anticipated. As the Probation Service strives to offer alternatives to custody, we had imagined that this additional disposal, providing a greater chance of avoiding imprisonment, would have been much more warmly received.

\section{The starting problems}

Our observations suggested that the few probation officers who were very opposed to our service, perhaps both because of the compulsory element of treatment and the medical orientation of the Clinic, greatly inhibited referrals from their fellow officers. We felt sure this was not a malicious process, but arose from the strength of their convictions. And their influential and powerful positions within the political system effectively cautioned against usage. However, we received nothing but support from senior probation managers. Fortunately, the judges and the magistrates seemed to welcome the new service and even suggested its use to others.

In order to combat the hesitancy from the probation service, we launched a series of visits to probation offices to explain our service and discuss any doubts that officers might have. These visits seemed appreciated. Doubts appeared reassured and subsequently success was signalled by greater referral. Yet not all were converted. Indeed, the patchy pattern of referral, even from the same offices, together with feedback from other sources, suggested that whether this treatment option was offered to an appropriate client often depended on the officer's attitude.

\section{The difficulties running the service}

The challenge for addicts of attempting to give up their drug taking while remaining in their community, in or close to the drug subculture, sometimes proved overwhelming of course. Similarly, resistance to confront relationship problems proved a prominent theme.

Another area of difficulty was ensuring consistency between the Clinic and the field probation officers. Some of the addicts were highly manipulative and were skilled at splitting the professionals involved. Indeed, some of the more persuasive individuals managed to recruit their probation officers to lobby the Clinic on their behalf for more favourable or lenient terms! Ongoing discussion and involving the local probation officers in the setting of treatment goals helped to minimise these risks. But certainly, some officers found it very difficult to set limits, perhaps because of their sympathies for their clients' desperate and sad plights.

However, it is noteworthy that we did not encounter any difficulties running the Clinic in a probation office. The probation staff were extremely supportive. There were no incidents and nor was there even any evidence of drug dealing in the waiting room!

\section{The demise of the service}

As expected, not all responded to the treatment and some failed to engage at all! When all rescue plans had been exhausted it was usually necessary to consider returning them to court as they had clearly breached the conditions of their probation orders. Such conclusions were reached reluctantly and only after full consultation with all involved. Their probation officer was supplied with a report detailing their clients' progress at the Clinic and any further psychiatric recommendations. This proved to be a stressful stage for their probation officer. Very few were actually breached. This was in spite of the knowledge that continued use invariably meant further offending.

Perhaps because of the disappointment wrought by accruing treatment failures, those officers who had always been opposed to our service had greater influence. Eventually, and only after deliberations at senior management level, the Greater Manchester Probation Service decreed that the compulsory nature of the Clinic had to end. Significantly, the probation service in their final communication concluded, "We ... no way regard the outcome so far as 
a failure." But, essentially, cited the problems as twofold. Firstly, many officers objected on grounds of ethics to the "compulsory treatment". And secondly, even many of those who had referred cases were against instigating breach proceedings. It was appreciated that the sentencing courts would have expected these noncompliant cases to be breached. Therefore the managers were concerned about eventually losing credibility with the courts. Moreover it was thought to be impractical to insist that the officers should "tighten up".

\section{Comment}

We greatly regretted the premature ending of our service. From the psychiatric perspective it seemed a success. Our resources to provide close supervision together with the opportunity of exerting a coercive but therapeutic cajolement of patients appeared to induce at least a degree of stability among very chaotic, distressed and desperate individuals. Of course, not all responded. But this was only expected, particularly in such a high risk group.

Our clinic failures were probably still using opiates and in order to finance their habits undoubtedly must have continued to offend. Therefore, we did not expect that the probation officers would find the consequent and necessary breach proceedings so objectionable. Certainly, we did not anticipate this would be the ultimate cause for the Clinic to close. Yet it is interesting that this issue may not be confined to this clinical problem (Lawson, 1979; Lewis, 1980).

As an interim conclusion, we consider that our clinic was a relative success and although onerous to all concerned, we felt it was worthwhile. However, for it to be feasible it would need a probation service willing to tolerate the ethical discomforts of enforcing the courts' obligations. Our experience confirms that where there is a will, the psychiatric and probation services can work closely and successfully together, even in such an emotive area as this!

\section{Acknowledgements}

We are indebted to our colleagues who ran the service with us: Dr Diane James, Mrs Margaret Lowe, Mrs Catherine Moran and Mrs Christine Rossen. All those who helped us set up this project are greatly appreciated, in particular, our psychiatric colleagues, Dr Angus Campbell and Dr John Strang, and our probation colleagues, Mr Royce Franklyn and Mr Michael Hindson. We are also grateful to all the probation officers who referred us cases, the judges and magistrates who were willing to consider our recommendations and not least, the patients who participated in the programme.

\section{References}

Lawson, C. (1978) The Probation Officer as Prosecutor: a study of Proceedings for Breach of Requirement in Probation, Cambridge: Institute of Criminology.

Lew/s, P. (1980) Psychiatric Probation Orders: Roles and Expectations of Probation Officers and Psychiatrists, Cambridge: Institute of Criminology.

WeBsTER, C. D. (1986) Compulsory treatment of narcotic addiction. International Journal of Law and Psychiatry, 8 , 133-159.

\section{Christmas Past in Psychiatry}

CHRISTMAS FESTIVITIES, AT THB

COUN'TY ASYLUM WOTTON, Nin: Gowan.

O. BATURDAT, Dedember, 28rd 1865.

WII BB GIVEN,

$\triangle$ ORAHD VOOAL ad INBTRUMBNTAL

CONCERT.

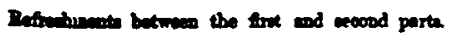

Co Fidey, Janong, Sh 1866.

THE CHRISTMAS BALL, AND GIGANIC

CHRISTMAS TREE,

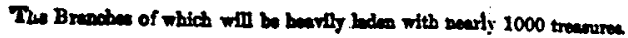
THE NEW THEATRE,

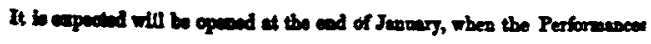
will oumes with the BCRrunang PARCES of

WHITEBAIT AT GREENWICH, $\infty$

BOX AND COX. 